\title{
Electrochemical and XPS studies of corrosion behaviour of a low carbon steel in the presence of FT2000 inhibitor
}

\author{
F. Kadirgan ${ }^{\mathrm{a}}$, S. Suzer ${ }^{\mathrm{b}, *}$ \\ a Department of Chemistry, Istanbul Technical University, 80626 Istanbul, Turkey \\ ${ }^{\mathrm{b}}$ Department of Chemistry, Bilkent University, Bilkent, 06533 Ankara, Turkey
}

Received 8 August 2000; received in revised form 6 September 2000; accepted 9 September 2000

\begin{abstract}
Corrosion behaviour of a new inhibitor (FT2000) is investigated in saline solution on a low carbon steel in the neutral aqueous media at $60^{\circ} \mathrm{C}$. Effect of sulphate ion is also studied. Corrosion rate, polarization resistance, and efficiency of the inhibitor are calculated. The nature of the protecting layer formed in the presence of the inhibitor is investigated by X-ray photoelectron spectroscopy, XPS. (C) 2001 Elsevier Science B.V. All rights reserved.
\end{abstract}

Keywords: Corrosion inhibitor; Low carbon steel; XPS

\section{Introduction}

Low carbon steel generally exhibits passive behaviour in neutral aqueous media and its corrosion is intimately connected with the properties of its passive surface oxide film [1,2]. Intensive corrosion is often observed due mainly to the aggressive properties of water which depend markedly on its hardness. Water with high carbonate hardness is, as a rule, non-aggressive, but it facilitates deposition of scale on pipes and heat exchange equipment. Soft water does not give rise to deposit of scale, but it is highly corrosive. On the other hand, corrosivity of the water is determined by its chloride and sulphate contents for steel as well as by its hardness salts. Passive metals generally corrode by processes occur-

*Corresponding author. Tel.: +90-312-2664946; fax: +90-3122664579. ring at, in or through a surface oxide film [3]. The mechanism of action of inhibitive anions on the corrosion of $\mathrm{Fe}$ in near neutral solution involves the following important steps:

- Reduction of the dissolution rate of the passivating oxide film

- Repair of the oxide film by promotion of the reformation of oxide

- Repair of the oxide film by plugging pores and coat the surface by insoluble compounds

- Prevention of the adsorption of aggressive anions

It has been observed that inhibition of metal corrosion occurred only when the initial rate of dissolution of metal oxides in solution of anions was less than a critical value.

In this work, corrosion inhibition behaviour of 
FT2000 on a low carbon steel is investigated by electrochemical and spectroscopic methods [4].

\section{Experimental}

Working electrode was the low carbon steel 220M07. It contained $0.15 \% \mathrm{C}, 0.9-1.3 \% \mathrm{Mn}, 0.2-$ $0.3 \% \mathrm{~S}$ and $0.07 \% \mathrm{P}$. Samples were cylinders of 0.5 $\mathrm{cm}$ diameter. They were polished mechanically and degreased with hot xylene and acetone before measurements. Corrosion measurements and Tafel analysis were carried out using a classical double-walled three electrode cell coupled to an EG\&G 273 potentiostat-galvanostat system. Potentiodynamic cathodic and anodic polarization curves were measured in $1 \% \mathrm{NaCl}$ and $0.5 \% \mathrm{Cl}^{-}+0.5 \% \mathrm{NO}_{3}^{-}+0.5 \%$ $\mathrm{SO}_{4}^{2-}$ solutions with and without the inhibitor in air at $60^{\circ} \mathrm{C}$ after immersion of the specimen for about 15 $\min$ and after the open-circuit potential became steady. The inhibitor (FT2000) contains organic and inorganic salts and was manufactured for use on some metals, such as $\mathrm{Al}, \mathrm{Cu}$, steel and brass in aqueous media. The $\mathrm{pH}$ of the solutions with inhibitor was always kept between 7 and 7.5. A platinum electrode and a saturated mercury sulphate electrode were used as counter and reference electrodes. Corrosion rates of specimens per year and polarisation resistances were calculated from Tafel analysis [5]. Surface characterisation using XPS was performed using a Kratos ES 300 spectrometer with $\mathrm{Mg} \mathrm{K} \alpha$ X-rays (1253.6 eV).

\section{Results and discussions}

A comparison of the corrosion potential of iron in neutral electrolytes, with the potentials for iron-oxide formation, indicates that for even just a slight shift in the potential to the positive side of the steady-state value, there will take place an oxidation reaction. Since this reaction is electrochemical for anodic polarization it will be accelerated, just like the ionization of the metal. The more positive the potential becomes, the greater will be the blanketing of the electrode with the oxide. When the passivation potential is reached, the electrode will almost be coated with an oxide layer. Since the migration of cations from the metal lattice into the solution through such an oxide layer is more difficult, the rate of the anodic process begins to drop. Metal ions may go into solution as a result of ordinary chemical reaction of oxide dissolution. If activating agents, such as chloride ions, are present in the electrolyte, then at pitting potential values, the passive state is disturbed and the process of anodic dissolution is accelerated. This is because the positive shift in potential enhances adsorption of the chloride ions. Since the coating of the surface with oxygen is non-uniform, in places where there are defects in the structure of the oxide film, adsorption of chloride ions will predominate. Thus, in addition to the passivating oxide, a halide possessing good solubility will also be formed. Pitting corrosion then sets in. This kind of corrosion can be suppressed with the aid of an inhibitor, which is able to prevent the adsorption of aggressive ions or to dislodge them from the metal surfaces.

Corrosion parameters can be calculated on the basis of potentiodynamic potential-current characteristics in the Tafel region $\left(E=E_{\text {corr }} \pm 250 \mathrm{mV}\right)$ and in the vicinity of the corrosion potential $(E=$ $E_{\text {corr }} \pm 20 \mathrm{mV}$ ) according to:

$\log j_{\mathrm{a}}=\log j_{\text {corr }}+\left(E_{\mathrm{j}}-E_{\text {corr }}\right) / b_{\mathrm{a}}$

$\log j_{\mathrm{c}}=\log j_{\text {corr }}+\left(E_{\text {corr }}-E_{\mathrm{j}}\right) / b_{\mathrm{c}}$

These equations corresponds to linear anodic and cathodic Tafel lines with slopes $b_{\mathrm{c}}=2.3 R T / a z F$ and $b_{\mathrm{a}}=2.3 R T /(1-a) z F$, where $R=$ gas constant, $z=$ number of transferred electrons, $a=$ transfer coefficient, $b_{\mathrm{a}}=$ anodic Tafel slope and $b_{\mathrm{c}}=$ cathodic Tafel slope. Current density $\left(j_{\text {corr }}\right)$ is determined by extrapolating the Tafel lines to $E=E_{\text {corr }}$ or according to the Stearn-Geary equation [6]. This results in:

$j_{\text {corr }}=b_{\mathrm{a}} \cdot b_{\mathrm{c}} / 2.3\left(b_{\mathrm{a}}+b_{\mathrm{c}}\right) R_{\mathrm{p}}=B / R_{\mathrm{p}}$

where $R_{\mathrm{p}}$ is the polarisation resistance, defined as the tangent of the curve at $E_{\text {corr }}$.

$R_{\mathrm{p}}=(\mathrm{d} E / \mathrm{d} j)_{E=E_{\text {corr }}}$

Once $j_{\text {corr }}$ is known, corrosion rate can be calculated using the conversion formula:

Corrosion rate $=C(E W / d)\left(j_{\text {corr }} / A\right)$ 


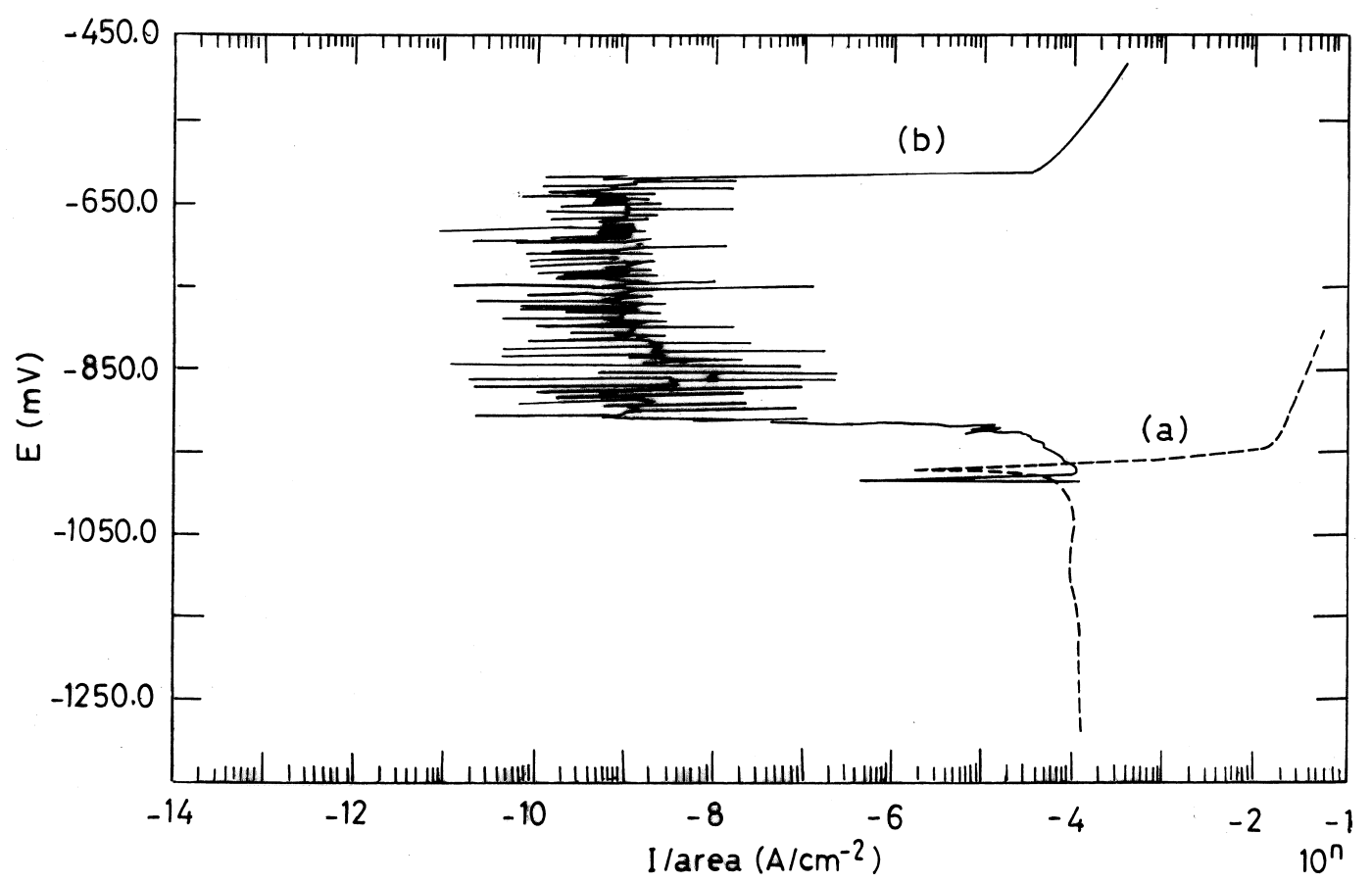

Fig. 1. Tafel plots of $\mathrm{Fe}$ in $1 \% \mathrm{NaCl}$ without (a) and with (b) the addition of the inhibitor at $60^{\circ} \mathrm{C}$.

where $E W$ is the equivalent weight of the sample in $\mathrm{g}, A$ is the sample area in $\mathrm{cm}^{2}, d$ is the density in $\mathrm{g} / \mathrm{ml}$, and $C$ is a conversion constant that is dependent upon the units desired. $C$ is $3.268 \times 10^{3}$ when $j_{\text {corr }}$ is in amperes and corrosion rate is desired in millimeters per year.

Fig. 1 shows the Tafel plots of $\mathrm{Fe}$ in $1 \% \mathrm{NaCl}$ without and with the addition of the same inhibitor. Results for $E_{\text {corr }}, j_{\text {corr }}$ and the Tafel constants calculated from $E-\log j$ curves obtained in the uninhibited and the inhibited $\mathrm{NaCl}$ solution at $60^{\circ} \mathrm{C}$ are listed in Table 1. Determination of $R_{\mathrm{p}}$ was carried out in the vicinity of $E_{\text {corr }}$ with a sweep of $0.1 \mathrm{mV} / \mathrm{s}$. The inhibiting efficiencies calculated using the equation:

$e=\left(1-j_{\text {corr }, \mathrm{i}} / j_{\text {corr }}\right)$

where, $j_{\text {corr }}, j_{\text {corr }, \mathrm{i}}, R_{\mathrm{p}}$ and $R_{\mathrm{p}, \mathrm{i}}$ are the corrosion current densities and the polarization resistances without and with inhibitor, respectively.

As it is seen from Fig. 1, for steel in $1 \% \mathrm{NaCl}$

Table 1

Corrosion parameters, inhibition efficiencies obtained by Tafel analysis and polarization resistances of the low carbon steel without and with the addition of the inhibitor at $60^{\circ} \mathrm{C}$

\begin{tabular}{|c|c|c|c|c|c|c|c|}
\hline Solution & $\begin{array}{l}E_{\text {corr }} \\
(\mathrm{mV} / \mathrm{MSE})\end{array}$ & $\begin{array}{l}j_{\text {corr }} \\
\left(\mu \mathrm{A} / \mathrm{cm}^{2}\right)\end{array}$ & $\begin{array}{l}b_{\mathrm{c}} \\
(\mathrm{mV})\end{array}$ & $\begin{array}{l}b_{\mathrm{a}} \\
(\mathrm{mV})\end{array}$ & $\epsilon$ & $\begin{array}{l}\text { Corrosion rate } \\
(\mathrm{mm} / \text { year })\end{array}$ & $\begin{array}{l}R_{\mathrm{p}} \\
(\Omega)\end{array}$ \\
\hline $1 \% \mathrm{NaCl}$ & -975.8 & 115.9 & 303 & 60.3 & - & $914.2 \times 10^{-3}$ & 52.18 \\
\hline $\begin{array}{l}1 \% \mathrm{NaCl}+\text { inh. } \\
0.5 \% \mathrm{NaCl}+\end{array}$ & -918 & $150.4 \times 10^{-3}$ & - & 284 & 0.998 & $1.2 \times 10^{-6}$ & 184.00 \\
\hline $\begin{array}{l}0.5 \% \mathrm{Na}_{2} \mathrm{SO}_{4} \\
0.5 \% \mathrm{NaCl}+\end{array}$ & -930 & 92.3 & 300 & 62.3 & - & $502 \times 10^{-3}$ & 18.2 \\
\hline $0.5 \% \mathrm{Na}_{2} \mathrm{SO}_{4}+$ inh. & -790 & $38.1 \times 10^{-3}$ & 104 & 414 & 0.999 & $3 \times 10^{-7}$ & 95.3 \\
\hline
\end{tabular}


solution, after corrosion potential $(\sim-975 \mathrm{mV})$ anodic current increases drastically indicating the dissolution from the surface. In the presence of the inhibitor, two corrosion potentials are obtained. At approximately $-995 \mathrm{mV}$, the current goes to small values $\left(\sim 10^{-7} \mathrm{~A} / \mathrm{cm}^{2}\right)$ reaching to first $E_{\text {corr }}$ potential which take place at some $\mathrm{mV}$ more negative values relative to the value without the inhibitor. Then, the surface is passivated and anodic current takes very small values. At $-920 \mathrm{mV}$, a second corrosion potential is observed while the current being approximately zero. The lower values of the current continue at a large potential interval indicating a complete passivation of the surface. Increasing the potential to the more positive values, the anodic current increases. However, the values are smaller than the currents obtained without the inhibitor media. The resistance polarization also increases in the presence of the inhibitor. Using the $0.5 \% \mathrm{NaCl}+$ $0.5 \% \mathrm{Na}_{2} \mathrm{SO}_{4}$ as corrosive electrolyte, even a higher inhibitor efficiency is observed.
In order to understand the nature of the passivating layer, we have recorded XPS spectra. In Fig. 2, XPS spectra of the steel (also immersed in pure water for $72 \mathrm{~h}$ ), steel immersed in $1 \% \mathrm{NaCl}$ solution, with and without application of the inhibitor are given. In addition to the usual O1s, N1s, C1s, Al2s and $2 \mathrm{p}$ peaks, $\mathrm{P}$ and $\mathrm{Si} 2 \mathrm{~s}$ and $2 \mathrm{p}$ peaks also appear in the samples which contain the inhibitor [7]. The most important feature of this figure is the absence of the $\mathrm{Cl} 2 \mathrm{p}$ peak in the sample which contains the inhibitor, whereas, the corresponding peak is present in the one immersed in the saline solution containing no inhibitor. The presence of a protective layer formation containing phosphate and silicate is also observed. So, the adsorption of activated ion is excluded on steel in the presence of the inhibitor depositing phosphate and silicate layer from electrolyte while the passivating oxide appears due to the interaction of the metal with oxygen. In the presence of phosphates, it is observed that, there are two passivation potentials on the anodic polarization curve: one of

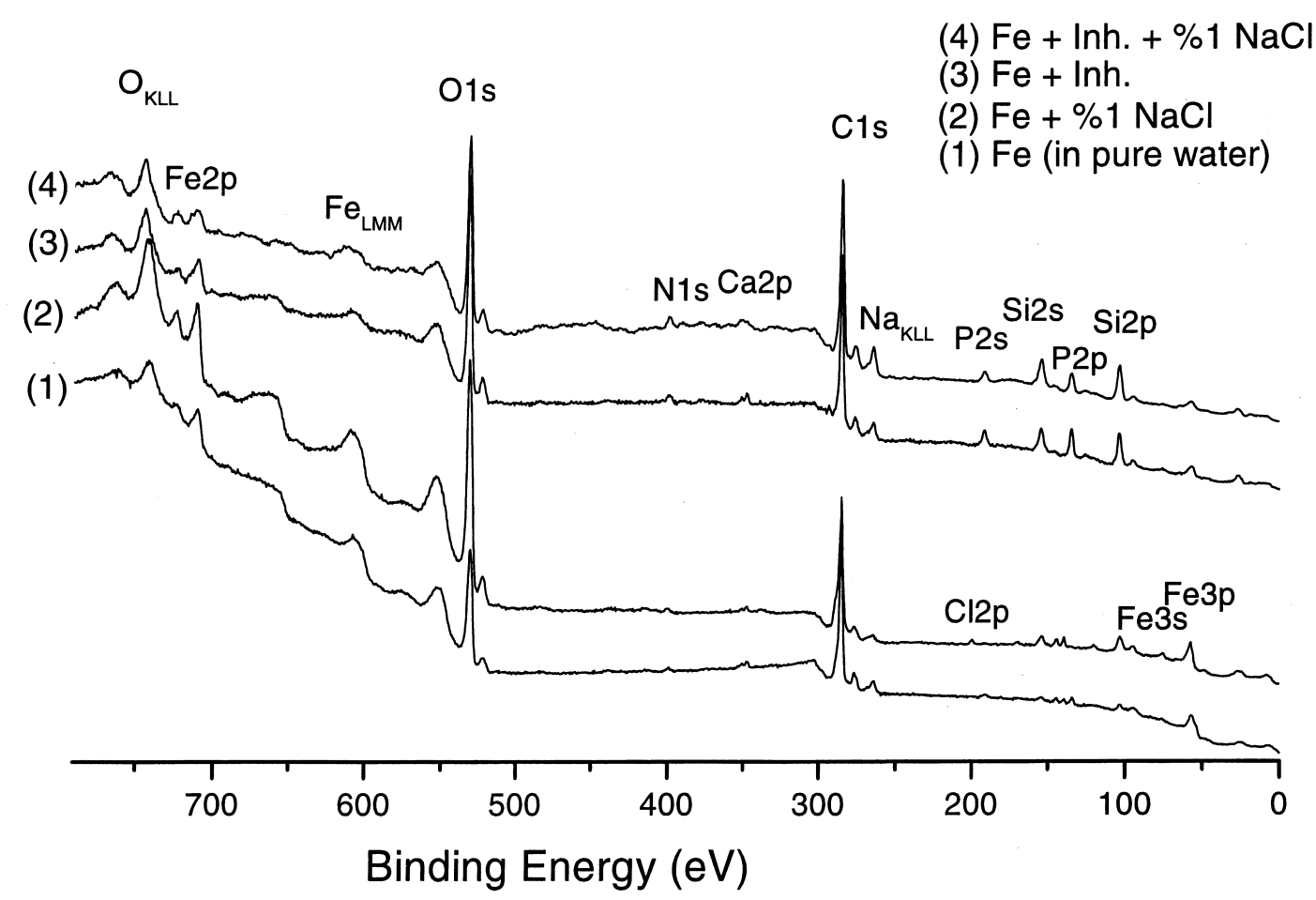

Fig. 2. XPS spectra of steel samples immersed (1) in pure water, (2) in a $1 \% \mathrm{NaCl}$ saline solution, (3) in a solution containing only the inhibitor, (4) in a $1 \% \mathrm{NaCl}$ saline solution containing also the inhibitor. 
these is shifted $0.2 \mathrm{~V}$ toward the negative in comparison with the potential of ordinary passivation observed in a without phosphate solution [8]. This led to conclusion that in phosphate solutions the transition of iron into the passive state is preceded by a specific passivation caused by the secondary deposition of metal phosphate from the solution. Accumulation of a poorly soluble iron phosphate on the steel surface creates conditions favourable for ordinary oxide passivation.

Taking into consideration these properties of the oxide layer, we assume that in the presence of inhibitor, these phosphate layers are formed on the sample. Two corrosion potentials observed may correspond to the formation of: (i) iron phosphate (at ca. $-0.99 \mathrm{~V}$ vs. MSE which is slightly negative than without the inhibitor media), and (ii) complete passivation with iron oxide formation (at ca. -0.92 $\mathrm{V}$ vs. MSE) in $1 \% \mathrm{NaCl}$ solution.

\section{Conclusions}

Based on the electrochemical and XPS data obtained in the present study, protective and passivating properties of FT2000 inhibitor is observed. The XPS spectra taken in immersed solutions for a certain time show the protective film formation containing phosphate and silicate ions on the low carbon steel. An increase of the polarization resistance also proves the protective properties of the inhibitor. Since the dissolution rate of this layer in combination with calcium existing in water is low and the surface film have an exceptionally high resistance to the transfer of electrons, corrosion rate of the metal is decreased in the corrosive media. Therefore, one can conclude that the oxide film of steel is repaired by plugging pores and coated by insoluble compounds and adsorption of aggressive anions is prevented.

\section{References}

[1] P.A. Malachesky, in: A.J. Bard (Ed.), Encyclopedia of Electrochemistry of the Elements, Vol. VI, Marcel Dekker, New York, 1976, p. 63.

[2] M. Pourbaix (Ed.), Atlas of Electrochemical Equilibria in Aqueous Solutions, Pergamon Press, Oxford, 1966, p. 168.

[3] K.J. Vetter, Electrochim. Acta 16 (1971) 1923.

[4] F. Kadirgan, Turkish patent (applied for).

[5] A.J. Bard, L.R. Faulkner, Electrochemical Methods, Wiley, New York, 1980.

[6] K.J. Vetter, Electrochemical Kinetics, Academic Press, New York, 1967.

[7] D. Briggs, M.P. Seah, 2nd Edition, Practical Surface Analysis, Vol. 1, Wiley, Chichester, 1996.

[8] I.L. Rozenfeld, Corrosion Inhibitors, McGraw-Hill, New York, 1981. 